\title{
CRESCIMENTO DE MUDAS DE PITANGUEIRA (Eugenia uniflora L.) EM SUBSTRATOS COM UTILIZAÇÃO DE SUPERFOSFATO SIMPLES
}

\author{
Seedling growing of surinan cherry (Eugenia uniflora L.) in different substrates \\ using simple super phosphate
}

\author{
Nildo Antônio Arruda de Abreu', Vander Mendonça², Breno Gonçalves Ferreira ${ }^{3}$, Glauco Antônio Teixeira ${ }^{4}$, \\ Henrique Antunes de Souza ${ }^{4}$, José Darlan Ramos ${ }^{5}$
}

\begin{abstract}
RESUMO
Conduziu-se este experimento com o objetivo de avaliar o crescimento de mudas tipo pé-franco de pitangueira em diferentes substratos com utilização de superfosfato simples conduzidos em um viveiro de formação de mudas localizado no Campus da Universidade Federal de Lavras (UFLA), Minas Gerais. Foram estudadas quatro doses de superfosfato simples $0 ; 2,5 ; 5$ e $10 \mathrm{~kg} \mathrm{~m}^{-3}$ de substrato e duas misturas de substratos: A (composto orgânico + areia + solo, na proporção de 1:1:3 em volume) e B (Plantmax ${ }^{\hat{a}}+\operatorname{areia}^{+}$solo, na proporção de 1:1:3 em volume). O delineamento experimental utilizado foi blocos ao acaso em esquema fatorial 4 x 2 , com 4 repetições e cinco plantas por parcela. Quando as mudas estavam em condições de serem enviadas a campo foram avaliadas pelas seguintes variáveis: altura da muda $(\mathrm{cm})$; comprimento de raiz $(\mathrm{cm})$, número de folha/planta, matéria seca da parte aérea, da raiz e total (g/planta). Com base nos resultados verificou-se que para a formação de mudas pé-franco de pitangueira, recomenda-se incorporar ao substrato o fertilizante superfosfato simples em dose de até $6 \mathrm{~kg} \mathrm{~m}^{-3}$ no substrato. Tanto o substrato A quanto o substrato B podem ser recomendados para a formação de mudas pé-franco de pitangueira.
\end{abstract}

Termos para indexação: Propagação, superfosfato simples, composto orgânico.

\begin{abstract}
This experiment was carried out in a nursery at orchard of Federal University of Lavras (UFLA), Minas Gerais state; in order to evaluate the growth seedling of Surinam cherry in different substrates using the simple super phosphate. The study involved four doses of simple super phosphate $0 ; 2,5 ; 5$ e $10 \mathrm{~kg} \mathrm{~m}^{-3}$. and two substrates mix: A (organic compost + sand + soil in 1:1:3 volume proportion) and B ( Plantmax + sand + soil 1:1:3 volume proportion) A randomized block design was used with factorial scheme $4 \times 2$, with four replications and five plants by plot. The plants were evaluated when they were in field condition by the following characteristic: high of plants $(\mathrm{cm})$; length of root $(\mathrm{cm})$; number of leaves/plant, dry matter of aerial part, root and total $(\mathrm{g} / \mathrm{plant})$. Through the results was verify that in seedling of Surinam cherry, it is recommended to mix to the substrate the fertilizer simple super phosphate until the dose $6 \mathrm{~kg} \mathrm{~m}^{-3}$. Both substrates A or B are recommended for seedling of Surinam cherry.
\end{abstract}

Index terms: Propagation, simple super phosphate, organic compost.

(Recebido para publicação em 18 de janeiro de 2005 e aprovado em 28 de junho de 2005)

\section{INTRODUÇÃO}

A pitangueira (Eugenia uniflora L.), família Myrtaceae, é uma fruteira nativa do Brasil, sendo bem adaptada às condições climáticas do Nordeste e encontrada em quase todo o território nacional. Devido a sua adaptabilidade às mais distintas condições de clima e solo, foi amplamente disseminada e é atualmente cultivada nas mais variadas regiões do globo como América do Sul e Central, Caribe, Flórida, Califórnia, Havaí, Sudeste da Ásia,
China, Índia, Sri Lanka, México, Madagascar, África do Sul, Israel e diversos países do Mediterrâneo (BEZERRA et al., 2000).

O principal método de propagação para a pitangueira é via semente (BEZERRA et al., 2000). Minami et al. (1994) consideram que $60 \%$ do sucesso de uma cultura está em implantá-la com mudas de alta qualidade, sendo a qualidade da muda responsável pelo vigor das plantas, pela produtividade e vida útil do pomar (CHALFUN \& PIO, 2002).

'Engenheiro Agrônomo M.Sc. Departamento de Agricultura - Universidade Federal de Lavras - Cx.P. 3037, 37.200-000 - Lavras, MG nildoabrel@yahoo.com.br

²Engenheiro Agrônomo, Dr. Prof. Adjunto da Universidade Estadual do Mato Grosso de Sul/UEMS - Rod. MS 306, Km 6 - 79.540-000 - Cassilândia, MS vanderm@uems.br

${ }^{3}$ Graduando em Agronomia pela Universidade de Três Corações/UNINCOR - Três Corações, MG.

${ }^{4}$ Graduandos em Agronomia pela Universidade Federal de Lavras/UFLA - Cx. P. 3037 - 37.200-000 - Lavras, MG.

${ }^{5}$ Engenheiro Agrônomo, Dr. Prof. Dep. de Agricultura/UFLA - Cx. P. 3037 - 37.200-000 - Lavras, MG - darlan@ufla.br 
Na formação das mudas, é importante a utilização de substratos que apresentem propriedades físico-químicas adequadas e que forneçam os nutrientes necessários para o desenvolvimento da planta (MENDONÇA et al., 2002). Testando substratos alternativos na formação de mudas de pitangueira, Carrijo et al. (2003) constataram que substratos esterco bovino: terra 1:1 e 1:2, terra: areia: esterco 1:1:1 e 2:1:1 em volume e Plantmax ${ }^{\hat{a}}$ promoveram maior crescimento da parte aérea das mudas de pitangueira. Segundo estes mesmos autores, o substrato Plantmax ${ }^{\hat{a}}$ demonstrou ser favorável em todas as variáveis analisadas. Entretanto, é um insumo caro, que onera o custo de produção da muda e não se encontra disponível para venda em qualquer lugar.

A adubação é uma prática extremamente importante não só na cultura racional da pitangueira, como de qualquer outra fruteira explorada comercialmente. Com uma adubação adequada e bem equilibrada, o produtor se beneficiará da qualidade dos frutos obtidos, do estado fitossanitário e do vigor das plantas, bem como da produtividade de seu pomar.

O fósforo é essencial para o crescimento normal das plantas e está entre os nutrientes com maior demanda. $\mathrm{O} P$ requerido para o ótimo crescimento das plantas varia conforme a espécie ou órgão analisado variando de 0,1 a 0,5\% da matéria seca (VICHIATO, 1996). Além de ajudar as raízes e as plântulas a se desenvolverem mais rapidamente, o fósforo aumenta a resistência aos rigores do inverno, melhora a eficiência no uso da água e favorece a resistência às doenças em algumas plantas (POTAFOS, 1998).

O uso do superfosfato simples é preferível no fornecimento de fósforo às plantas, pois além do fósforo, este fertilizante contém na sua composição química, cálcio (25-28\% CaO) e enxofre (12\%) (CARMELLO, 1995).

Conduziu-se este experimento com o objetivo de avaliar o crescimento de mudas do tipo pé-franco de pitangueira em diferentes substratos com superfosfato simples.

\section{MATERIAL E MÉTODOS}

$\mathrm{O}$ experimento foi conduzido no pomar da Universidade Federal de Lavras (UFLA) Minas Gerais, em um viveiro telado $(50 \%)$ utilizado para formação de mudas durante o período de maio a setembro de 2004.

Os frutos de pitangueira foram coletados de três plantas do tipo pé-franco localizadas no município de Lavras-MG. Em seguida extraiu-se as sementes, que passaram pelo processo de limpeza em água corrente e secaram à sombra por dois dias. Logo em seguida, as sementes foram semeadas em sacos plásticos de dimensões de 10 x $20 \mathrm{~cm}$ com capacidade de $650 \mathrm{~cm}^{3}$ os quais foram enchidos com as misturas de substratos, previamente adubadas com as doses do superfostato simples testadas neste trabalho. Foi também adicionado aos substratos calcário dolomítico para elevação o índice de saturação por base a $70 \%$. Foram semeadas duas sementes por recipiente e, cerca de vinte dias após a emergência, realizou-se o desbaste deixando-se apenas a plântula mais vigorosa. Não foi feito nenhum tipo de poda nas mudas, sendo conduzidas livremente até a época da avaliação.

Os tratos culturais utilizados nas mudas durante a condução do experimento foram irrigação (de manhã e a tarde), controle de pragas e doenças e, a monda das plantas daninhas. A adubação de cobertura, via foliar, foi realizada quinzenalmente, iniciando após o desbaste com aplicação de nitrogênio, sendo utilizado a uréia $(0,2 \%)$ como fonte. Esta adubação de cobertura foi repetida 4 vezes durante a condução das mudas.

Foram testadas quatro doses de superfosfato simples 0; 2,5; 5 e $10 \mathrm{~kg} \mathrm{~m}^{-3}$ de substrato, com $180 \mathrm{~g} \mathrm{de}_{2}$ $\mathrm{O}_{5}$ por $\mathrm{Kg}^{-1}$ e duas misturas de substratos: A (Composto orgânico + areia + solo, na proporção de 1:1:3 em volume) e B (Plantmax ${ }^{\hat{a}}+$ areia + solo, na proporção de 1:1:3 em volume). O delineamento experimental utilizado foi blocos ao acaso em esquema fatorial 4 x 2 , com 4 repetições e cinco plantas por parcela. Os resultados da análise química das misturas, realizados antes da aplicação do superfosfato simples, encontram-se nas Tabelas 1 e 2.

As variáveis avaliadas, aos 180 dias após a semeadura, foram: altura de muda $(\mathrm{cm})$, medida a partir do colo da planta até a gema apical; número de folha/planta; comprimento de raiz. A altura da muda foi obtida medindose a distância entre o colo e o ápice da muda. $\mathrm{O}$ comprimento da raiz foi obtido medindo-se a distância entre o colo e a extremidade da raiz pivotante.

Posteriormente as partes foram colocadas em estufa à temperatura de $65^{\circ} \mathrm{C}$, até atingir peso constante. Após isso, foram efetuadas pesagens para a estimativa dos teores de matéria seca dos componentes: raiz, parte aérea (folhas) e total (raízes + parte aérea), respectivamente.

Os dados foram submetidos à análise de variância, em seguida as médias dos dados qualitativos foram comparadas pelo do teste Tukey, ao nível de 5\% de probabilidade. Para as médias dos dados quantitativos foi utilizada a análise de regressão, sendo usada a equação quadrática por ser a que melhor se ajustou aos dados (GOMES, 2000). As análises foram realizadas pelo programa computacional Sistema para Análise de Variância - SISVAR (FERREIRA, 2000). 
TABELA 1 - Resultados da análise físico-química dos substratos utilizados no experimento com pitangueira, realizada pelo Laboratório de Fertilidade do Solo da UFLA ${ }^{1}$.

\begin{tabular}{|c|c|c|c|c|c|c|c|c|c|c|c|c|c|}
\hline Substrato & pH & $\mathbf{P}$ & $\mathbf{K}$ & $\mathbf{C a}$ & Mg & Al & H+Al & SB & $\mathbf{t}$ & $\mathbf{T}$ & V & M.O & P-rem \\
\hline & $\mathrm{H}_{2} \mathrm{O}$ & & & & & & $\mathrm{cmol}_{\mathrm{c}} \mathrm{C} \mathrm{C}$ & & & & dag.kg ${ }^{-1}$ & $(\%)$ & $\mathrm{mg} \mathrm{L}^{-1}$ \\
\hline A & 6,0 & 15 & 72 & 4,0 & 1,4 & 0,0 & 1,9 & 5,6 & 5,6 & 7,5 & 74,6 & 1,6 & 15,1 \\
\hline B & 5,7 & 49,8 & 186 & 5,1 & 1,8 & 0,0 & 2,3 & 7,4 & 7,4 & 9,6 & 76,2 & 1,9 & 12,2 \\
\hline
\end{tabular}

TABELA 2 - Resultados da análise de micronutrientes nos substratos no experimento com pitangueira, realizada pelo Laboratório de Fertilidade do Solo da UFLA.

\begin{tabular}{cccllll}
\hline Substrato & Zn & Fe & Mn & Cu & B & S \\
\hline & & \multicolumn{7}{c}{$\mathrm{mg} \mathrm{dm}^{-3}$} \\
A & 3,4 & 49,6 & 20,7 & 2,0 & 1,0 & 13,8 \\
B & 1,9 & 118,2 & 23,1 & 2,1 & 0,9 & 29,3 \\
\hline
\end{tabular}

\section{RESULTADOS E DISCUSSÃO}

A aplicação de doses de superfosfato simples, aos substratos estudados, teve efeito significativo $(\mathrm{P}<0,01)$ para a altura da muda, comprimento da raiz, matéria seca da raiz, matéria seca da parte aérea e matéria seca total. $\mathrm{O}$ substrato não teve efeito sobre nenhuma das características e a interação foi significativa $(\mathrm{P}<0,05)$ apenas para a altura da muda e o comprimento da raiz. $\mathrm{O}$ número de folhas não foi influenciado por nenhum dos tratamentos (Tabela 3).

Na Figura 1, observa-se que, conforme o aumento as doses de superfosfato simples aplicadas, ocorreu um aumento da altura das mudas. As mudas apresentaram altura máxima estimada de $16,5 \mathrm{~cm}$ quando foi aplicada a dose de $5,4 \mathrm{~kg} \mathrm{~m}^{-3}$ no substrato A e altura máxima estimada de 16,45 $\mathrm{cm}$ quando foi aplicada a dose de $4,6 \mathrm{~kg} \mathrm{~m}^{-3}$ no substrato B. A partir destas dosagens houve um efeito contrário, caracterizado como super dosagem.

De acordo com Malavolta et al. (1974), o fósforo tem participação essencial na fotossíntese, respiração, degradação de açúcares e no armazenamento, transferência e utilização de energia para processos vitais da planta, além de participar na divisão celular. Devido a isso, com o aumento da quantidade de fósforo absorvida pelas plantas, ocorre um aumento na atividade metabólica, favorecendo o crescimento destas como um todo.

Para o comprimento da raiz a dose de superfosfato simples máxima estimada de $4,7 \mathrm{~kg} \mathrm{~m}^{-3}$ no substrato A proporcionou um comprimento de $17,8 \mathrm{~cm}$ nas raízes e no substrato $B$ a resposta seguiu um comportamento linear decrescente, em que a melhor resposta para o comprimento de raiz $(17,81 \mathrm{~cm})$ foi sem a utilização do fertilizante (Figura 2). Se comparar os substratos na dose $0 \mathrm{~kg} \mathrm{~m}^{-3}$ de superfosfato simples, verifica-se que o substrato B proporcionou maior comprimento de raiz. Esta resposta pode, em parte, ser justificada em função de um maior teor inicial de fósforo $\left(49,8 \mathrm{mg} \mathrm{dm}^{-3}\right)$ apresentado por este substrato na sua composição, como está demonstrado na Tabela 1.

A utilização dos diferentes tratamentos não influenciou no número de folhas de mudas pé-franco de pitangueira que apresentou, em média, 12 folhas por planta na época da avaliação deste trabalho.

O valor máximo estimado para a matéria seca da parte aérea foi de $1,45 \mathrm{~g}$ quando foi aplicado o superfosfato simples na dose de $5,64 \mathrm{~kg} \mathrm{~m}^{-3}$ no substrato (Figura 3). 
TABELA 3 - Resultado da análise de variância para altura da muda (AM), comprimento da raiz (CR), número de folhas (NF), matéria seca da raiz (MSR), matéria seca da parte aérea (MSPA) e matéria seca total (MST) em função das doses de superfosfato simples (SS) e dos substratos (S) na produção de mudas pé-franco de pitangueira. Lavras, MG, 2004.

\begin{tabular}{lccccccc}
\hline $\begin{array}{l}\text { Fontes de } \\
\text { Variação }\end{array}$ & GL & AM (cm) & CR (cm) & NF & MSR (g) & MSPA (g) & MST (g) \\
\hline SS (SS) & 3 & $11,58278^{* *}$ & $6,19237^{* *}$ & $10,014^{\mathrm{ns}}$ & $0,77996^{* *}$ & $0,10862^{* *}$ & $1,46598^{* *}$ \\
(S) & 1 & $0,393828^{\mathrm{ns}}$ & $0,21615^{\mathrm{ns}}$ & $2,7144^{\mathrm{ns}}$ & $0,23719^{\mathrm{ns}}$ & $0,000007^{\mathrm{ns}}$ & $0,20834^{\mathrm{ns}}$ \\
SS x S & 3 & $6,39225^{*}$ & $1,82289^{*}$ & $1,4261^{\mathrm{ns}}$ & $0,14565^{\mathrm{ns}}$ & $0,02529^{\mathrm{ns}}$ & $0,19451^{\mathrm{ns}}$ \\
Bloco & 3 & 3,1001 & 5,3603 & 5,09236 & 0,06173 & 0,01785 & 0,15204 \\
Resíduo & 18 & 1,3329 & 0,50122 & 3,99016 & 0,18017 & 0,01786 & 0,27297 \\
\hline CV(\%) & & 7,56 & 4,16 & 16,65 & 38,42 & 32,55 & 34,64 \\
\hline
\end{tabular}

${ }^{\text {ns }}$ Não-significativo. ${ }^{*} \mathrm{e}^{* *}$ Significativo a $5 \%$ e $1 \%$ de probabilidade pelo teste $\mathrm{F}$.

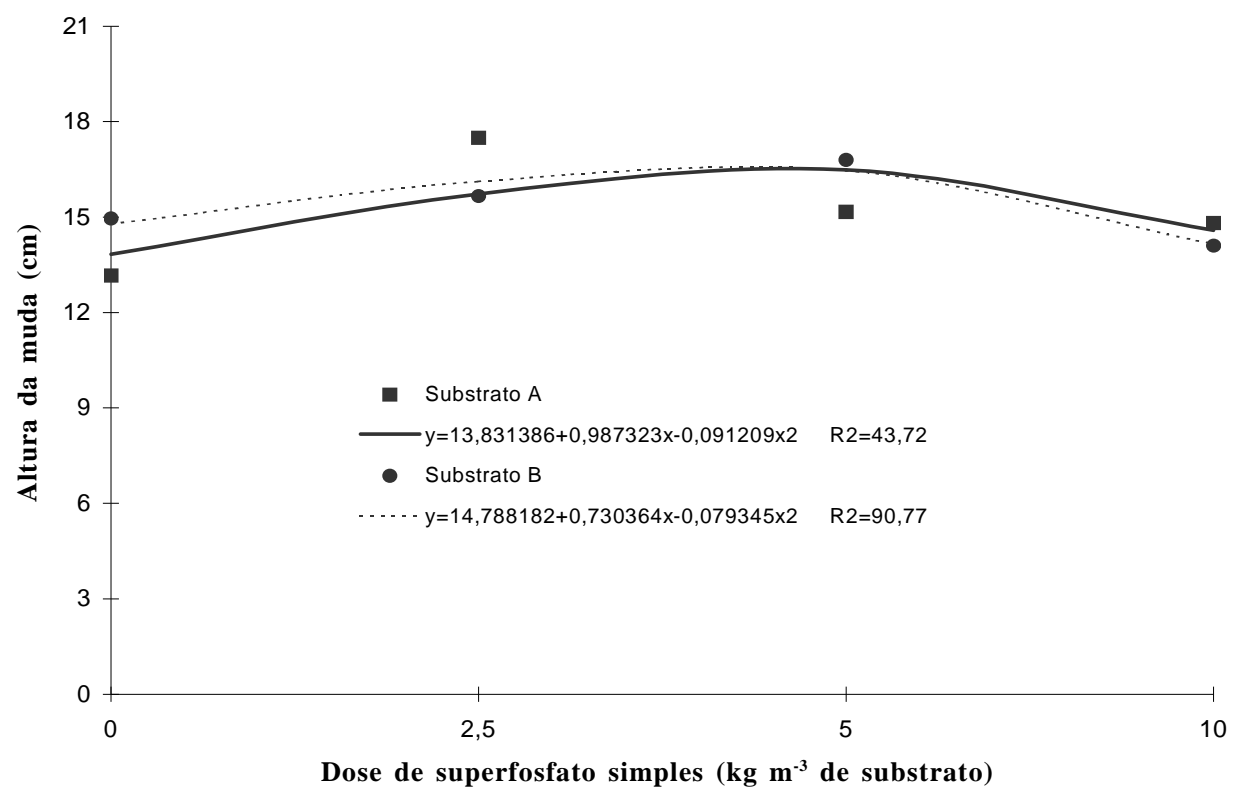

FIGURA 1 - Efeito das doses de superfosfato simples e dos substratos na altura de mudas pé-franco de pitangueira. Lavras-MG, 2004.

Ciênc. agrotec., Lavras, v. 29, n. 6, p. 1117-1124, nov./dez., 2005 


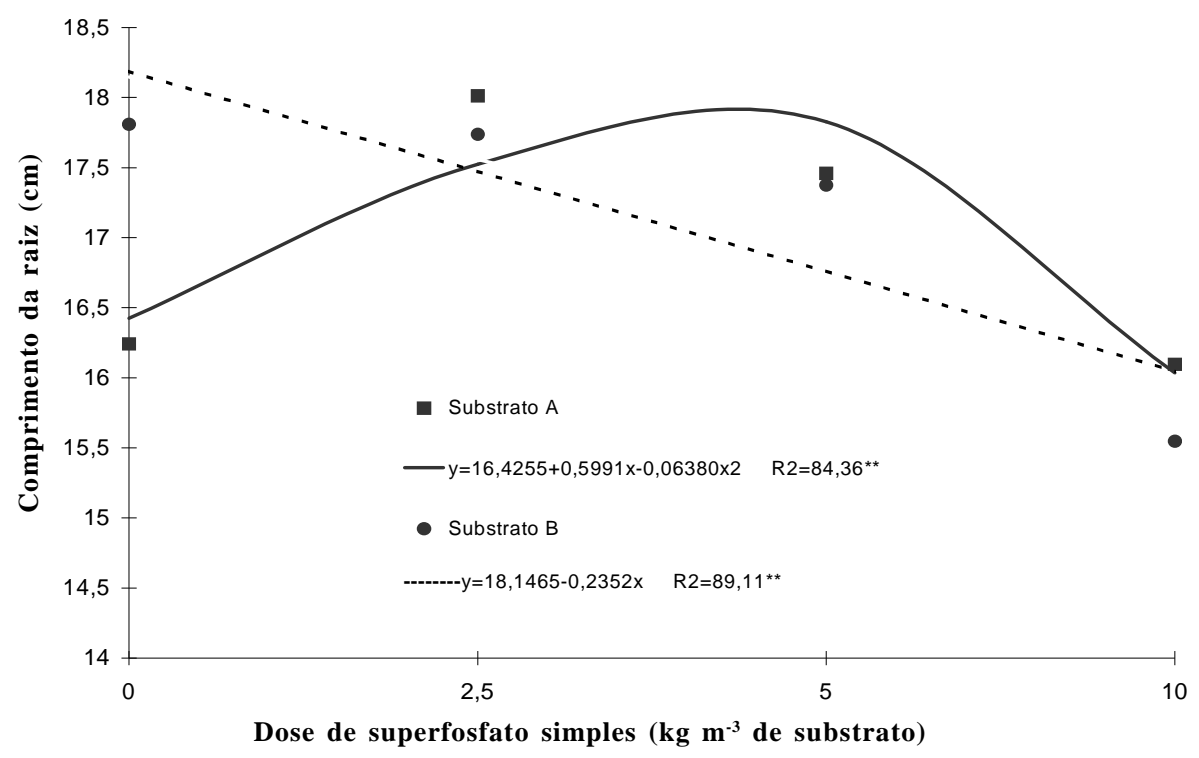

FIGURA 2 - Efeito das doses de superfosfato simples e dos substratos no comprimento de raiz de mudas pé-franco de pitangueira. Lavras-MG, 2004.

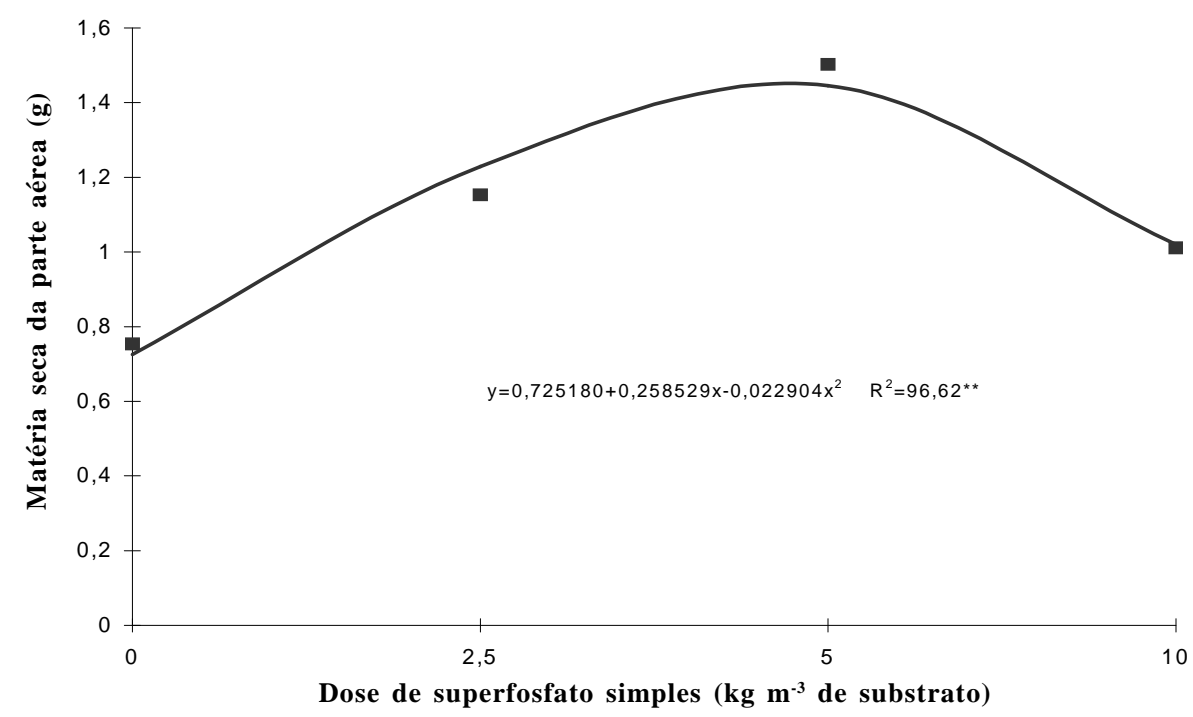

FIGURA 3 - Efeito das doses de superfosfato simples na matéria seca da parte aérea de mudas pé-franco de pitangueira. Lavras-MG, 2004. 
Para a matéria seca da raiz (Figura 4) a melhor resposta $(0,53 \mathrm{~g})$ foi observada quando foi aplicado o superfosfato simples na dose de $6,04 \mathrm{~kg} \mathrm{~m}^{-3}$ no substrato (Figura 4).

Cardoso et al. (1992) utilizando aplicações de superfosfato simples $(1,25 ; 2,5$ e $5,0 \mathrm{~g})$ também constataram incrementos na altura e na matéria seca da parte aérea de mudas de cafeeiro 'Mundo Novo' e 'Catuaí em recipientes.

A matéria seca total teve melhor resposta $(1,98 \mathrm{~g})$ quando foi aplicado o superfosfato simples na dose de $5,69 \mathrm{~kg} \mathrm{~m}^{-3}$ no substrato (Figura 5).

Trabalhando com a aplicação de $\mathrm{P}_{2} \mathrm{O}_{5}$ no substrato, para a formação de mudas de aceroleira, Souza et al. (1998), constataram ganhos significativos com a presença deste mineral no desenvolvimento das plantas.
Souza et al. (2003) também verificaram que a aplicação de superfosfato simples na dose de $5 \mathrm{~kg} \mathrm{~m}^{-3}$ de substrato com $40 \%$ de vermicomposto proporcionaram a obtenção de mudas de gravioleira com qualidade superiores às demais e que doses de superfosfato simples acima de $5,0 \mathrm{~kg} \mathrm{~m}^{-3}$ promovem efeitos negativos.

As culturas diferem grandemente na sua habilidade para extrair formas disponíveis de fósforo no solo. Assim, pode-se ter ganhos ou não com a aplicação de fósforo na produção de mudas frutíferas, dependendo assim da espécie em questão (LOPES, 1998).

Quanto aos substratos utilizados, observou-se pequenas diferenças. Entretanto, ao se verificar as Tabelas 1 e 2, observa-se que o substrato B foi o que apresentou valores mais acentuados em relação a quase todos os nutrientes, principalmente em relação ao $\mathrm{P}, \mathrm{K}, \mathrm{Ca}$ e Mg.

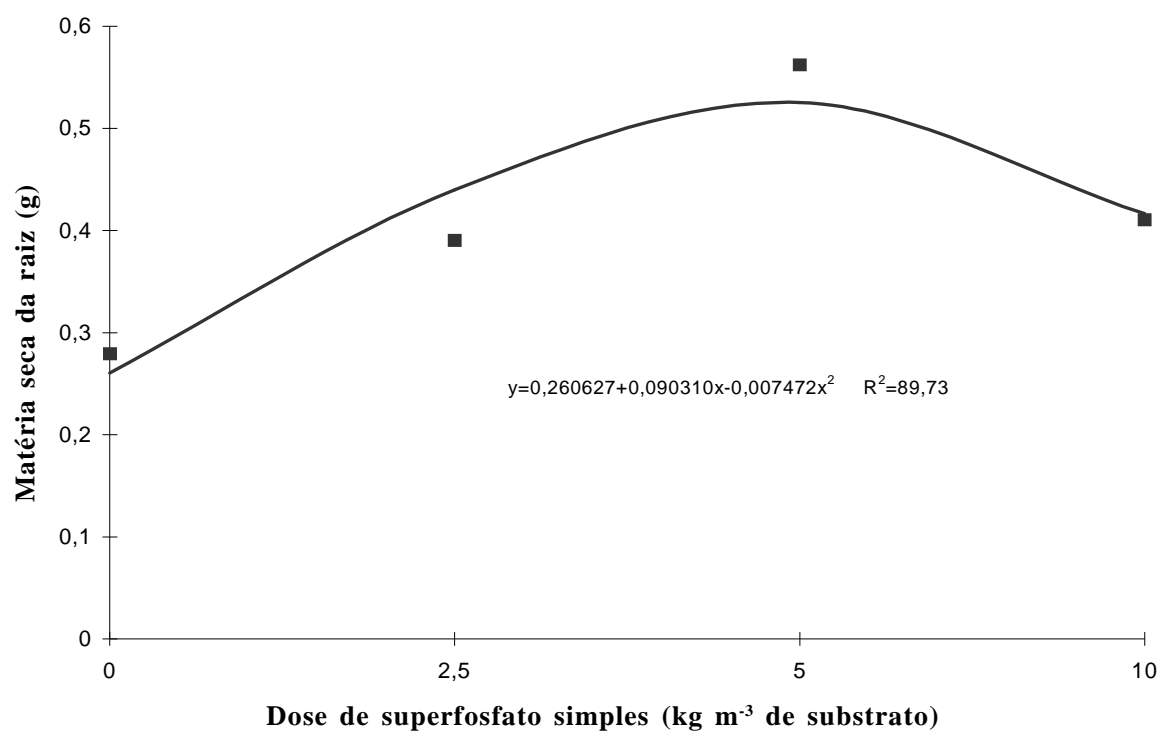

FIGURA 4 - Efeito das doses de superfosfato simples na matéria seca da raiz de mudas pé-franco de pitangueira. Lavras-MG, 2004.

Ciênc. agrotec., Lavras, v. 29, n. 6, p. 1117-1124, nov./dez., 2005 


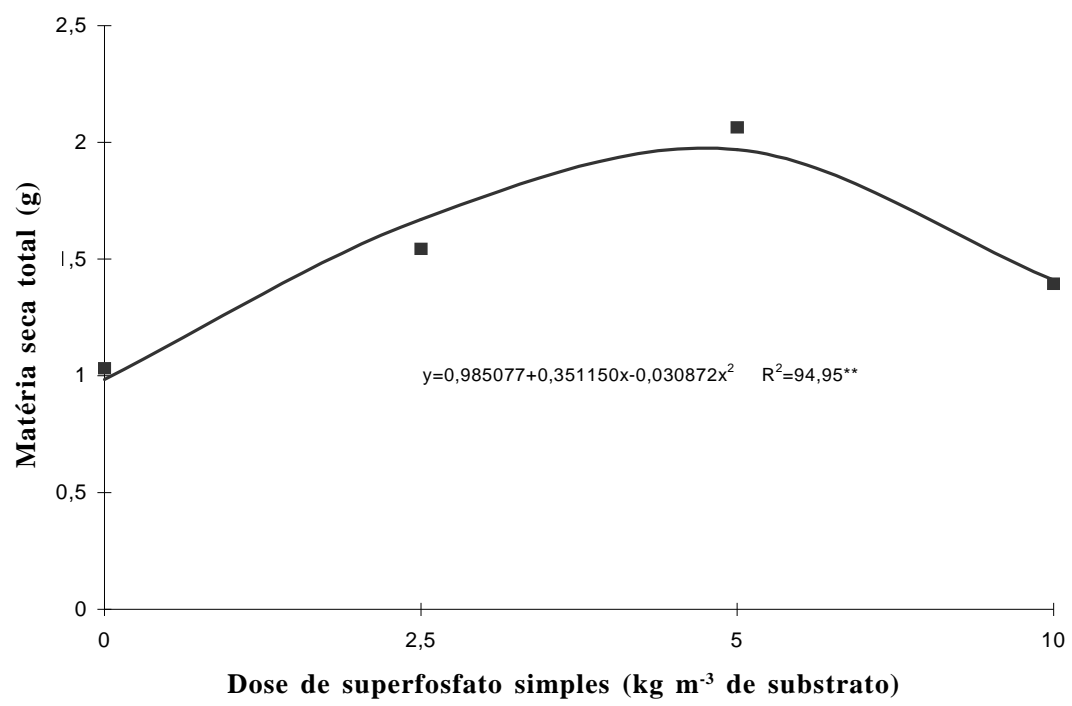

FIGURA 5 - Efeito das doses de superfosfato simples na matéria seca total de mudas pé-franco de pitangueira. Lavras-MG, 2004.

\section{CONCLUSÕES}

Para a formação de mudas pé-franco de pitangueira, recomenda-se incorporar ao substrato o fertilizante superfosfato simples em dose de até $5 \mathrm{~kg} \mathrm{~m}^{-3}$ no substrato.

Os substratos utilizados não tiveram efeito sobre nenhuma das características avaliadas neste trabalho.

\section{REFERÊNCIAS BIBLIOGRÁFICAS}

BEZERRA, J. E. F.; SILVA JÚNIOR, J. F. da; LEDERMAN, I. E. Pitanga (Eugenia uniflora L.). Jaboticabal: Funep, 2000. 30 p. (Série Frutas Nativas, 1).

CARDOSO, E. L.; ALVARENGA, G.; CARDOSO, M. M. de; CARVALHO, J. G. de. Efeito de doses de superfosfato simples em substrato, sobre o desenvolvimento de mudas de cafeeiro (Coffea arabica L.) "Mundo Novo" e "Catuaí". Ciência e Prática, Lavras, v. 16, n. 1, p. 35-38, 1992.

CARMELLO, Q. A. de C. Nutrição e adubação de mudas hortícolas. In: MINAMI, Q. (Ed.). Produção de mudas de alta qualidade em horticultura. São Paulo: T. A. Queiroz, 1995. p. 27-37.

CARRIJO, E. P.; PIO, R.; RAMOS, J. D.; GONTIJO, T. C. A.; VILELA, S. de A.; MENDONÇA, V. Substratos alternativos na formação de mudas de pitangueira. In:
CONGRESSO DOS PÓS-GRADUANDOS DA UFLA, 12. 2003, Lavras. Anais... Lavras: APG, 2003. CD-ROM.

CHALFUN, N. N. J.; PIO, R. Aquisição e plantio de mudas frutíferas. Lavras: UFLA, 2002. 19 p. (Boletim técnico, 113).

FERREIRA, D. F. Análise estatística por meio do SISVAR (Sistema para Análise de Variância) para Windows versão 4.0. In: REUNIÃO ANUAL DA REGIÃO BRASILEIRA DA SOCIEDADE INTERNACIONAL DE BIOMETRIA, 45., 2000, São Carlos. Anais... São Carlos: UFSCar, 2000. p. 255258 .

GOMES, F. P. Curso de estatística experimental. 14. ed. Piracicaba: USP, 2000. 477 p.

INSTITUTO DA POTASSA \& FOSFATO. Manual internacional de fertilidade do solo. Tradução de A. S. Lopes. 2. ed. rev. e ampl. Piracicaba, 1998. 177 p.

LOPES, A. S. Manual de fertilidade do solo. Piracicaba: Fundação Cargill, 1989. 177 p.

MALAVOLTA, E.; HAAG, H. P.; MELLO, F. A. F.; BRASIL SOBRINHO, M. O. C. Nutrição mineral e adubação de plantas cultivadas. São Paulo: Pioneira, 1974. 272 p. 
MENDONÇA, V.; RAMOS, J. D.; ARAÚJO NETO, S. E. de; PIO, R.; GONTIJO, T. C. A.; JUNQUEIRA, K. P. Substratos e quebra de dormência na formação do portaenxerto de gravioleira cv. RBR. Revista Ceres, Viçosa, v. 49, n. 286, p. 657-668, nov./dez. 2002.

MINAMI, K.; TESSARIOLI NETO, J.; PENTEADO, S. R.; ESCARPARI FILHO, J. A.Produção de mudas hortícolas de alta qualidade. Piracicaba: ESALQ/SEBRAE, 1994. 155 p.

SOUZA, C. A. S.; CORRÊA, F. L. de O.; CARVALHO, J. G. de; MENDONÇA, V. Efeito do fósforo e do zinco no crescimento e nutrição de mudas de acerola (Malpighia glabra L.). In: CONGRESSO BRASILEIRO DE
FRUTICUlTURA, 15., 1998, Poços de Caldas. Anais... Poços de Caldas: SBF, 1998. p. 62.

SOUZA, C. A. S.; CORRÊA, F. L. de O.; MENDONÇA, V.; CARVALHO, J. G. de. Crescimento de mudas de gravioleira (Anonna muricata L.) em substrato com superfosfato simples e vermicomposto. Revista Brasileira de Fruticultura, Jaboticabal, v. 25, n. 3, p. 453-456, 2003.

VICHIATO, M. Influência da fertilização do porta-enxerto tangerineira (Citrus reshni Hort. Ex Tan. cv. Cleópatra) em tubetes, até a repicagem. 1996. 82 f. Dissertação (Mestrado em Agronomia) - Universidade Federal de Lavras, Lavras, 1996. 